\title{
Neuroprotective Effects of Purpurin Against Ischemic Damage via MAPKs, Bax, and Oxidative Stress Cascades in the Gerbil Hippocampus
}

\author{
Woosuk Kim ${ }^{1,2} \cdot$ Hyun Jung Kwon ${ }^{1,3} \cdot$ Hyo Young Jung ${ }^{4,5} \cdot K_{y u} \mathrm{Ri} \mathrm{Hahn}^{4} \cdot$ Yeo Sung Yoon ${ }^{4}$ In Koo Hwang ${ }^{4}$. \\ Soo Young Choi ${ }^{1}$ - Dae Won Kim ${ }^{3}$ D
}

Received: 6 August 2021 / Accepted: 7 November 2021 / Published online: 30 January 2022

(C) The Author(s) 2022

\begin{abstract}
Purpurin has various effects, including anti-inflammatory effects, and can efficiently cross the blood-brain barrier. In the present study, we investigated the effects of purpurin on oxidative stress in HT22 cells and mild brain damage in the gerbil hippocampal CA1 region induced by transient forebrain ischemia. Oxidative stress induced by $\mathrm{H}_{2} \mathrm{O}_{2}$ was significantly ameliorated by treatment with purpurin, based on changes in cell death, DNA fragmentation, formation of reactive oxygen species, and pro-apoptotic (Bax)/anti-apoptotic (Bcl-2) protein levels. In addition, treatment with purpurin significantly reduced the phosphorylation of c-Jun N-terminal kinase (JNK), extracellular signal-regulated kinase 1/2 (ERK), and p38 signaling in HT22 cells. Transient forebrain ischemia in gerbils led to a significant increase in locomotor activity 1 day after ischemia and significant decrease in number of surviving cells in the CA1 region 4 days after ischemia. Administration of purpurin reduced the travel distance 1 day after ischemia and abrogates the neuronal death in the hippocampal CA1 region 4 days after ischemia based on immunohistochemical and histochemical staining for NeuN and Fluoro-Jade C, respectively. Purpurin treatment significantly decreased the activation of microglia and astrocytes as well as the increases of nuclear factor kappa-light-chain-enhancer of activated B cells p65 in the hippocampal CA1 region 4 days after ischemia and ameliorated the ischemia-induced transient increases of interleukin (IL)-1 $\beta$, IL-6, and tumor necrosis factor (TNF)- $\alpha$ in the hippocampus $6 \mathrm{~h}$ after ischemia. In addition, purpurin significantly alleviated the ischemia-induced phosphorylation of JNK, ERK, and p38 in the hippocampus 1 day after ischemia. Furthermore, purpurin treatment significantly mitigated the increases of Bax in the hippocampus 1 day after ischemia and the lipid peroxidation based on malondialdehyde and hydroperoxides levels 2 days after ischemia. These results suggest that purpurin can be one of the potential candidates to reduce neuronal damage and inflammatory responses after oxidative stress in HT22 cells or ischemic damage in gerbils.
\end{abstract}

Keywords Purpurin $\cdot$ Ischemia $\cdot$ Hippocampus $\cdot$ Microglia $\cdot$ Bax $\cdot$ Pro-inflammatory cytokine $\cdot$ MAPKs

Soo Young Choi

sychoi@hallym.ac.kr

$\triangle$ Dae Won Kim

kimdw@gwnu.ac.kr

1 Department of Biomedical Sciences, Research Institute for Bioscience and Biotechnology, Hallym University, Chuncheon 24252, South Korea

2 Department of Anatomy, College of Veterinary Medicine, and Veterinary Science Research Institute, Konkuk University, Seoul 05030, South Korea
3 Department of Biochemistry and Molecular Biology, Research Institute of Oral Sciences, College of Dentistry, Gangneung-Wonju National University, Gangneung 25457, South Korea

4 Department of Anatomy and Cell Biology, College of Veterinary Medicine, and Research Institute for Veterinary Science, Seoul National University, Seoul 08826, South Korea

5 Department of Veterinary Medicine \& Institute of Veterinary Science, Chungnam National University, Daejeon, South Korea 


\section{Introduction}

Ischemic stroke is a life-threatening disease that affects approximately 15 million people worldwide annually [1]. Interruption of the blood flow into the brain causes a reduction in the supply of oxygen and glucose into the brain, resulting in damage to affected areas, including the hippocampus [2, 3]. Reperfusion of interrupted vessels into the brain enormously increases the blood supply to the brain, but glucose metabolism is impaired via the pyruvate dehydrogenase pathway in neurons and pyruvate carboxylase pathway in astrocytes [4]. Normally, oxygen radicals are generated from $0.2-2 \%$ of oxygen by the electron transport chain [5] and scavenged by antioxidants in the body [6, 7]. However, ischemia/reperfusion significantly increases the formation of oxygen radicals, exceeding the scavenging capacity of antioxidant enzymes in neurons, and finally causing oxidative damage and propagating inflammatory damage in neurons after ischemia $[8,9]$.

Many attempts have been made to prevent and reduce brain damage after ischemic damage using herbal extracts because of their high phenolic and flavonoid contents [10, 11]. Anthraquinones have a 9,10-dioxoanthracene core substituted with phenolic hydroxyl and aliphatic groups in the two benzene rings. Anthraquinones are less highlighted, although they have various biological effects that inhibit the progression of diseases [12]. Purpurin, an anthraquinone, exhibits antioxidant, anti-inflammatory, and antifungal effects in in vitro assays $[13,14]$ and antiangiogenic effects in a zebrafish model [15]. In addition, purpurin inhibits monoamine oxidase and shows potential for drug development in depression [16, 17]. Purpurin is able to cross the blood-brain barrier (BBB) assessed in human brain-like endothelial cells [18], which mimic the in vivo BBB [19].

However, few studies have been conducted to elucidate the effects of purpurin against brain damage. A recent study demonstrated the neuroprotective effects of purpurin against Alzheimer's disease-like symptoms [18], but no studies have examined the effects of purpurin against ischemic damage. Transient forebrain ischemia only causes less severe damage to brain compared to focal ischemia. Similarly, hydrogen peroxide $\left(\mathrm{H}_{2} \mathrm{O}_{2}\right)$ induces oxidative stress and mild neuronal damage in HT22 cells compared to oxygen and glucose deprivation, which is comparable to focal ischemic models in rodents. In addition, several studies demonstrated temporal and spatial patterns of oxidative stress in the brain of gerbils after ischemia [20,21]. In the present study, we elucidated the effects of purpurin and its mechanisms based on $\mathrm{H}_{2} \mathrm{O}_{2}$-induced oxidative stress in HT22 cells and ischemia-induced neuronal damage in the gerbil hippocampal CA1 region.

\section{Materials and Methods}

\section{Cell preparation and Determination of Cellular Toxicity in HT22 cells}

Murine hippocampal HT22 cells were obtained from ATCC (Manassas, VA, USA) and cultured in Dulbecco's modified Eagle's medium as described in previous studies [22, 23]. Purpurin was dissolved in $200-\mathrm{mM}$ dimethyl sulfoxide (DMSO) and various concentrations of purpurin $(1-200 \mu \mathrm{M})$ were added to HT22 cells for $60 \mathrm{~min}$. The cells were then harvested to observe the cellular toxicity of purpurin in HT22 cells. Cellular toxicity was assessed by measuring the fluorescence of formazan produced using the WST-1 assay kit (Sigma, St. Louis, MO, USA) and a Fluoroskan ELISA plate reader (Labsystems Multiskan MCC/340, Helsinki, Finland) as described in previous studies [22, 23].

\section{Measurements of Reactive Oxygen Species, DNA Fragmentation, and Cell Viability in HT22 Cells}

Cells were exposed to $25-\mu \mathrm{M}$ purpurin or 200-mM DMSO immediately after treatment with $1-\mathrm{mM} \mathrm{H}_{2} \mathrm{O}_{2}$. For reactive oxygen species (ROS) formation, $20-\mu \mathrm{M} 2^{\prime}, 7^{\prime}$-dichlorofluorescein diacetate (DCF-DA, Invitrogen Molecular Probes, Eugene, OR, USA) was added to HT22 cells at 10 min after $\mathrm{H}_{2} \mathrm{O}_{2}$ treatment to induce the formation of DCF, which has strong fluorescence. Cells were harvested $30 \mathrm{~min}$ after DCFDA treatment. DNA fragmentation was validated using terminal deoxynucleotidyl transferase dUTP nick end labeling (TUNEL) staining as described in previous studies [22, 23]. Briefly, cells were harvested at $3 \mathrm{~h}$ after $\mathrm{H}_{2} \mathrm{O}_{2}$ treatment, and DNA fragmentation was visualized using a TUNEL staining kit (Sigma). Microphotographs from DCF-DA and TUNEL staining were taken using a confocal fluorescence microscope (LSM 510 META NLO; Zeiss GmbH, Jena, Germany), and the fluorescence intensity was measured using a Fluoroskan ELISA plate reader (Labsystems Multiskan MCC/340). Cell death was assessed using a WST-1 assay at $5 \mathrm{~h}$ after $\mathrm{H}_{2} \mathrm{O}_{2}$ treatment, and formazan fluorescence was measured using a Fluoroskan ELISA plate reader.

\section{Western Blot Analysis in HT22 cells}

To elucidate the possible mechanisms of purpurin's effects against oxidative stress, cells were harvested $2 \mathrm{~h}$ after $\mathrm{H}_{2} \mathrm{O}_{2}$ treatment. Thereafter, cells were lysed with ice-cold radioimmunoprecipitation assay buffer (Thermo Scientific, IL, USA), and western blotting for mitogen-activated protein kinases (MAPKs) was performed as described in a previous study [24]. Briefly, the following primary antibodies were used: rabbit anti-c-Jun N-terminal kinase (JNK), p-JNK, 
anti-extracellular signal-regulated kinase $1 / 2$ (ERK), antip-ERK, anti-p38, and anti-p-p38, Bax, Bcl-2, and $\beta$-actin (1:2,000; Abcam, Cambridge, UK). All antibodies except $\beta$-actin were purchased from Cell Signaling (Danvers, MA, USA) and used at the same dilution (1:1000).

\section{Experimental Animals}

Mongolian gerbils (male, 3 months old) were obtained from Japan SLC Inc. (Shizuoka, Japan), and the experimental protocols were approved by the Institutional Animal Care and Use Committee (IACUC) of Seoul National University (SNU-200313-2). Ischemic surgery was conducted as described in previous studies [22-24]. Briefly, animals were anesthetized with $2.5 \%$ isoflurane (Hana Pharm, Co., Ltd, Hwaseong, South Korea) and both common carotid arteries in neck region were exposed and they were occluded with non-traumatic vascular clip (Roboz Surgical Instrument Co., Gaithersburg, MD, USA) for 5 min. Obstruction and reperfusion of both common carotid arteries was confirmed by observing the retina artery using an ophthalmoscope (Heine Optotechnik, Herrsching, Germany). Immediately after ischemia/reperfusion, vehicle (saline containing $0.5 \%$ sodium carboxymethyl cellulose), 1, 3, or $6 \mathrm{mg} / \mathrm{kg}$ 1,2,4-trihydroxyanthraquinone (purpurin, Sigma, St. Louis, MO) was orally administered to gerbils. The dosage was chosen based on the antidepressant-like effects of $6 \mathrm{mg} / \mathrm{kg}$ purpurin treatment in mice [17]. In addition, we did not use DMSO as a vehicle for in vivo studies because it shows neuroprotective effects against ischemic damage [25].

\section{Spontaneous Motor Activity}

Motor activity was monitored 1 day after ischemia for $60 \mathrm{~min}$ because hyperactivity was induced days 1 and 2 after ischemia due to functional damage in the hippocampal CA1 region [26]. In contrast, morphological damage was evident in the hippocampal CA1 region 4 days after ischemia. Traveling activity was recorded using a digital camera system (Basler 106,200, Ahrensburg, Germany), and the travel distance and duration of immobile/mobile phases were analyzed using EthoVision XT 14 (Wageningen, the Netherlands).

\section{Neuronal Death, Survival and Inflammatory Responses}

Neuronal death and survival were assessed using histochemical and immunohistochemical staining for Fluoro-Jade $\mathrm{C}$ and neuronal nuclei (NeuN), respectively, as described previously [23]; Lee et al., 2020]. In addition, inflammatory responses such as glial (microglia and astrocyte) activation and nuclear factor kappa-light-chain-enhancer of activated $\mathrm{B}$ cells $(\mathrm{NF}-\kappa \mathrm{B})$ expression were visualized by immunohistochemical staining for ionized calcium-binding adapter molecule 1 (Iba-1), glial fibrillary acid protein (GFAP), and NF- $\mathrm{kB}$, respectively, as described previously $[21,27]$. Briefly, the animals were sacrificed with a mixture of alfaxalone (Alfaxan, $75 \mathrm{mg} / \mathrm{kg}$; Careside, Seongnam, South Korea) and xylazine (10 mg/kg; Bayer Korea, Seoul, South Korea) 4 days after ischemia and perfused transcardially with saline and $4 \%$ paraformaldehyde. Coronal serial Sects. (30- $\mu \mathrm{m}$ thickness) were made based on brain atlas between 2.0 and $2.7 \mathrm{~mm}$ caudal to the bregma [28]; Three to five Sects. (90 $\mu \mathrm{m}$ apart from each other) were incubated with mouse anti-NeuN antibody (1:1000; EMD Millipore, Temecula, CA, USA), rabbit anti-Iba-1 antibody (1:500; Wako, Osaka, Japan), glial fibrillary acid protein (GFAP, 1:1,000; EMD Millipore), and rabbit anti-NF- $\mathrm{KB}(1: 1,100$; Abcam). Sections were reacted with 3,3'-diaminobenzidine tetrachloride (Sigma) to visualize immunoreactive signals. For Fluoro-Jade C staining, the sections attached to gelatincoated slide were sequentially incubated in $0.06 \%$ potassium permanganate for $20 \mathrm{~min}$ and in $0.0001 \%$ Fluoro-Jade $\mathrm{C}$ (Biosensis, Thebarton, SA, Australia). The number of NeuN-immunoreactive neurons and Fluoro-Jade $C$ stained cells was calculated using OPTIMAS software (version 6.5; CyberMetrics ${ }^{\circledR}$ Corporation, Phoenix, AZ, USA). Iba1, GFAP, and NF-кB immunoreactivities were quantified based on pixel number and gray scale using ImageJ software version 1.80 (National Institutes of Health, Bethesda, MD, USA).

\section{Measurements of Pro-inflammatory Cytokines}

To elucidate the mechanisms of purpurin's effects against ischemic damage, animals ( $n=5$ in each group) were euthanized with $75 \mathrm{mg} / \mathrm{kg}$ alfaxalone and $10 \mathrm{mg} / \mathrm{kg}$ xylazine $6 \mathrm{~h}$ and 4 days after ischemia/reperfusion, when pro-inflammatory cytokine levels were significantly increased and returned to control levels, respectively [29, 30]. In brief, interleukin (IL)-1 $\beta$, IL-6, and tumor necrosis factor (TNF)- $\alpha$ levels were measured in the hippocampus based on comparisons with linear calibration curves generated using IL- $1 \beta$, IL-6, and TNF- $\alpha$ standard solutions by using their respective enzyme immunoassay kits (BioSource International Inc., Camarillo, CA, USA).

\section{Measurements of MAPK, Bax, and Oxidative Stress in Gerbil Hippocampus}

To elucidate the MAPKs and Bax pathway in gerbil hippocampus after ischemia, animals were sacrificed $24 \mathrm{~h}$ after ischemia. Oxidative stress induced by transient ischemia was assessed in the hippocampus 2 days after by measurements of malondialdehyde (MDA) and lipid hydroperoxides levels, 
which were used as indicators of lipid peroxidation to elucidate the effects of purpurin on MAPK/oxidative stress pathway. Hippocampi were obtained from the brain and homogenized. Western blotting for MAPKs, Bcl-2, and Bax was performed described above. In addition, the concentration of MDA was analyzed using the LPO-586 kit (Calbiochem, La Jolla, CA, USA) and lipid hydroperoxides were measured with ferrous oxidation-xylenol orange assay in the hippocampal homogenates described by a previous study [20].

\section{Statistical Analysis}

All measurements were performed in order to ensure objectivity in blind conditions, by two observers for each experiment, carrying out the measures of control and experimental samples under the same conditions. Data are presented as mean with the standard deviation, and differences in means were compared and statistically analyzed using one-way or two-way analysis of variance (ANOVA) followed by Bonferroni's post hoc test using GraphPad Prism 5.01 software (GraphPad Software, Inc., La Jolla, CA, USA).

\section{Results}

\section{Neuroprotective Effects of Purpurin Against Oxidative Stress in HT2 Cells}

First, we validated the toxicity of purpurin in HT22 cells to determine the effective, but non-toxic, concentration of purpurin. Purpurin treatment for $60 \mathrm{~min}$ showed no toxic effects at a concentration $25 \mu \mathrm{M}$, and higher concentrations of purpurin decreased cell viability in a concentration-dependent manner (Fig. 1A).

ROS formation was visualized by the formation of DCF fluorescence after $\mathrm{H}_{2} \mathrm{O}_{2}$ treatment of HT22 cells. In the control group, DCF fluorescence was faintly detected, but in the DMSO-treated group, some cells showed strong DCF fluorescence, although no statistically significant difference in DCF fluorescence was detected between the control and DMSO-treated groups. In the DMSO and $\mathrm{H}_{2} \mathrm{O}_{2}$-treated $\left(\mathrm{H}_{2} \mathrm{O}_{2}+\mathrm{DMSO}\right)$ group, numerous DCF fluorescent cells were found, and the fluorescence intensity was significantly higher (511.3\%) than that in the control group. In the purpurin and $\mathrm{H}_{2} \mathrm{O}_{2}$-treated $\left(\mathrm{H}_{2} \mathrm{O}_{2}+\right.$ Purpurin) group, a few DCF fluorescent cells were found, and fluorescence intensity was significantly lower than that in the $\mathrm{H}_{2} \mathrm{O}_{2}+$ DMSO group (Fig. 1B).

DNA fragmentation was observed using TUNEL staining after $\mathrm{H}_{2} \mathrm{O}_{2}$ treatment of HT22 cells. In the control and DMSO groups, few TUNEL-positive cells were detectable among the HT22 cells and the TUNEL fluorescence intensity was low. In the $\mathrm{H}_{2} \mathrm{O}_{2}+$ DMSO group, many
TUNEL-positive cells were observed among HT22 cells, and the fluorescence intensity was significantly increased to $490.3 \%$ of that in the control group. In the $\mathrm{H}_{2} \mathrm{O}_{2}+$ Purpurin group, few TUNEL-positive cells were found, and the fluorescence intensity was significantly lower than that in the $\mathrm{H}_{2} \mathrm{O}_{2}+$ DMSO group at $201.5 \%$ of the intensity in the control group (Fig. 1C).

Cell viability was measured using formazan fluorescence from tetrazolium salts after $\mathrm{H}_{2} \mathrm{O}_{2}$ treatment in HT22 cells. In the DMSO group, the cell viability was similar to that of the control group, but cell viability in the $\mathrm{H}_{2} \mathrm{O}_{2}+$ DMSO group was significantly lower after $\mathrm{H}_{2} \mathrm{O}_{2}$ treatment at $56.6 \%$ of that of the control group. In the $\mathrm{H}_{2} \mathrm{O}_{2}+$ Purpurin group, cell viability was significantly increased compared to that in the $\mathrm{H}_{2} \mathrm{O}_{2}+$ DMSO group, and cell viability in this group was at $78.3 \%$ of that of the control group (Fig. 1D).

\section{Neuroprotective Mechanisms of Purpurin Against Oxidative Stress in HT2 cells}

$\mathrm{Bax}$ and $\mathrm{Bcl}-2$ protein levels were measured using western blotting after $\mathrm{H}_{2} \mathrm{O}_{2}$ treatment of HT22 cells. In the DMSO group, Bax and $\mathrm{Bcl}-2$ protein levels did not show any significant changes relative to those in the control group. However, in the $\mathrm{H}_{2} \mathrm{O}_{2}+$ DMSO group, Bax protein levels were significantly higher at $469.7 \%$ of those in the control group, while Bcl-2 levels were dramatically lower at $24.2 \%$ of those in the control group. In the $\mathrm{H}_{2} \mathrm{O}_{2}+$ Purpurin group, changes in $\mathrm{Bax}$ and $\mathrm{Bcl}-2$ levels were ameliorated compared to those in the $\mathrm{H}_{2} \mathrm{O}_{2}+$ DMSO group, respectively, and they were $336.5 \%$ and $55.9 \%$ of those in the control group, respectively (Fig. 2A).

JNK, ERK, p38 proteins, and their phosphorylated forms (p-JNK, p-ERK1/2, and p-p38) were assessed using western blotting after $\mathrm{H}_{2} \mathrm{O}_{2}$ treatment of HT22 cells, and the ratio of phosphorylated and naïve forms were analyzed. In the DMSO group, the p-JNK/JNK, p-ERK/ERK, and p-p38/ p38 ratios were similar to those in the control group. In the $\mathrm{H}_{2} \mathrm{O}_{2}+$ DMSO group, the p-JNK/JNK, p-ERK/ERK, and p-p38/p38 ratios were significantly higher at $381.8 \%$, $472.3 \%$, and $176.4 \%$ of those in the control group, respectively. In the $\mathrm{H}_{2} \mathrm{O}_{2}+$ Purpurin group, the ratio of p-JNK/ JNK, p-ERK/ERK, and p-p38/p38 was significantly lower than those in the $\mathrm{H}_{2} \mathrm{O}_{2}+$ DMSO group at $222.2 \%, 283.5 \%$, and $109.7 \%$ of the ratios in the control group, respectively (Fig. 2B).

\section{Neuroprotective Effects of Purpurin Against Ischemic Damage in Gerbils}

The neuroprotective effects of purpurin were validated using locomotor behavior 1 day after ischemia. In the vehicletreated ischemic group, the time in the mobile and immobile 
Fig. 1 Effects of purpurin against oxidative damage in HT22 cells. A Concentrationdependent WST-1 assay was performed in HT22 cells to determine the optimal concentration to show minimal neurotoxicity. B ROS formation, C DNA fragmentation, and $\mathbf{D}$ cell damage was assessed after $\mathrm{H}_{2} \mathrm{O}_{2}$-induced oxidative stress in HT22 cells using DCF staining, TUNEL staining, and WST-1 assay. Scale bar $=50 \mu \mathrm{m}$. DCF and TUNEL fluorescent intensities were observed using an enzyme-linked immunosorbent assay (ELISA) reader. Data are expressed as mean value \pm standard deviation and were analyzed using one-way ANOVA followed by Bonferroni's post hoc test ( ${ }^{\mathrm{a}} p<0.05$, significantly different from the control group; ${ }^{\mathrm{b}} p<0.05$, significantly different from the DMSO group; ${ }^{c} p<0.05$, significantly different from the $\mathrm{H}_{2} \mathrm{O}_{2}+$ DMSO group)
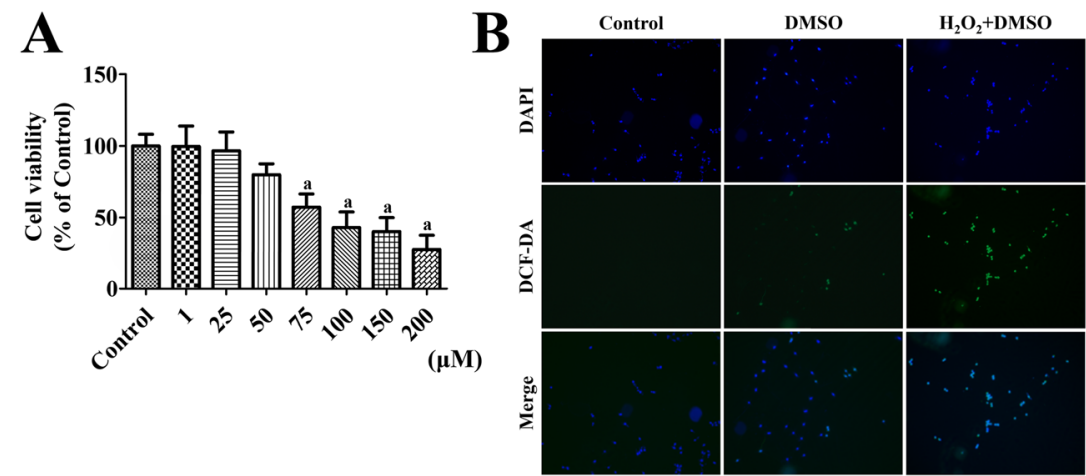

$\mathrm{H}_{2} \mathrm{O}_{2}+$ Purpurin
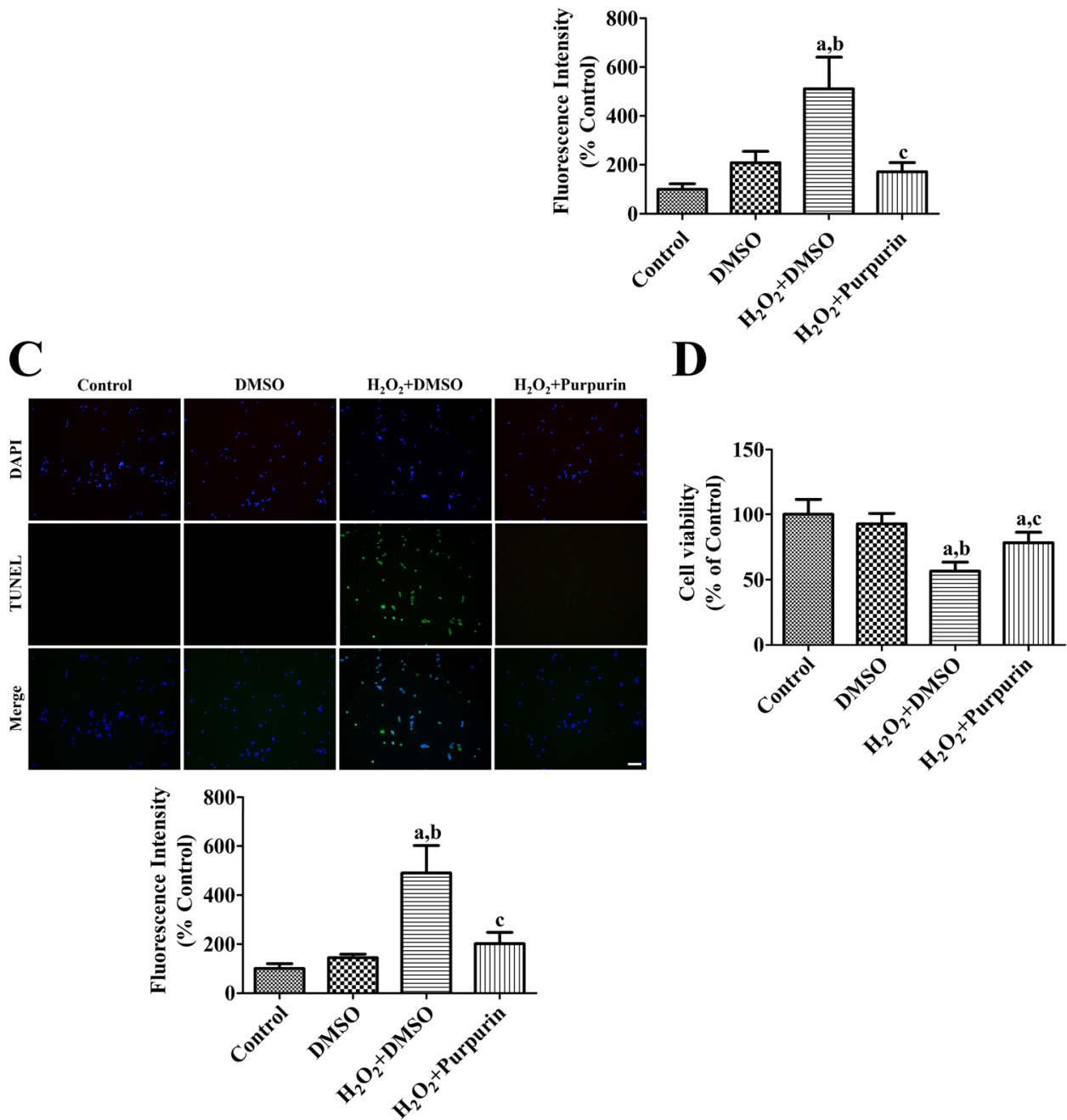

phases was significantly changed to $115.6 \%$ and $57.3 \%$ of those in the control group, respectively. The traveled distance in the vehicle-treated ischemic group was significantly longer than that in the control group (292.9\% of that in the control group). In the 1 or $3 \mathrm{mg} / \mathrm{kg}$ purpurin-treated ischemic groups, the time spent in the mobile and non-mobile phases was similar to those in the vehicle-treated group, but in the $6 \mathrm{mg} / \mathrm{kg}$ purpurin-treated group, they did not show significant differences compared to those in the vehicle-treated group control or vehicle-treated ischemic group. Similarly, the traveled distance was significantly longer in 1 or $3 \mathrm{mg} / \mathrm{kg}$ purpurin-treated ischemic groups than in the control group. However, in the $6 \mathrm{mg} / \mathrm{kg}$ purpurin-treated group, the traveled distance was significantly less than that in the vehicle- or $1 \mathrm{mg} / \mathrm{kg}$ purpurin-treated ischemic groups (181.9\% of that in the control group) (Fig. 3A).

The neuroprotective effects of purpurin were confirmed using immunohistochemical and histochemical staining for 


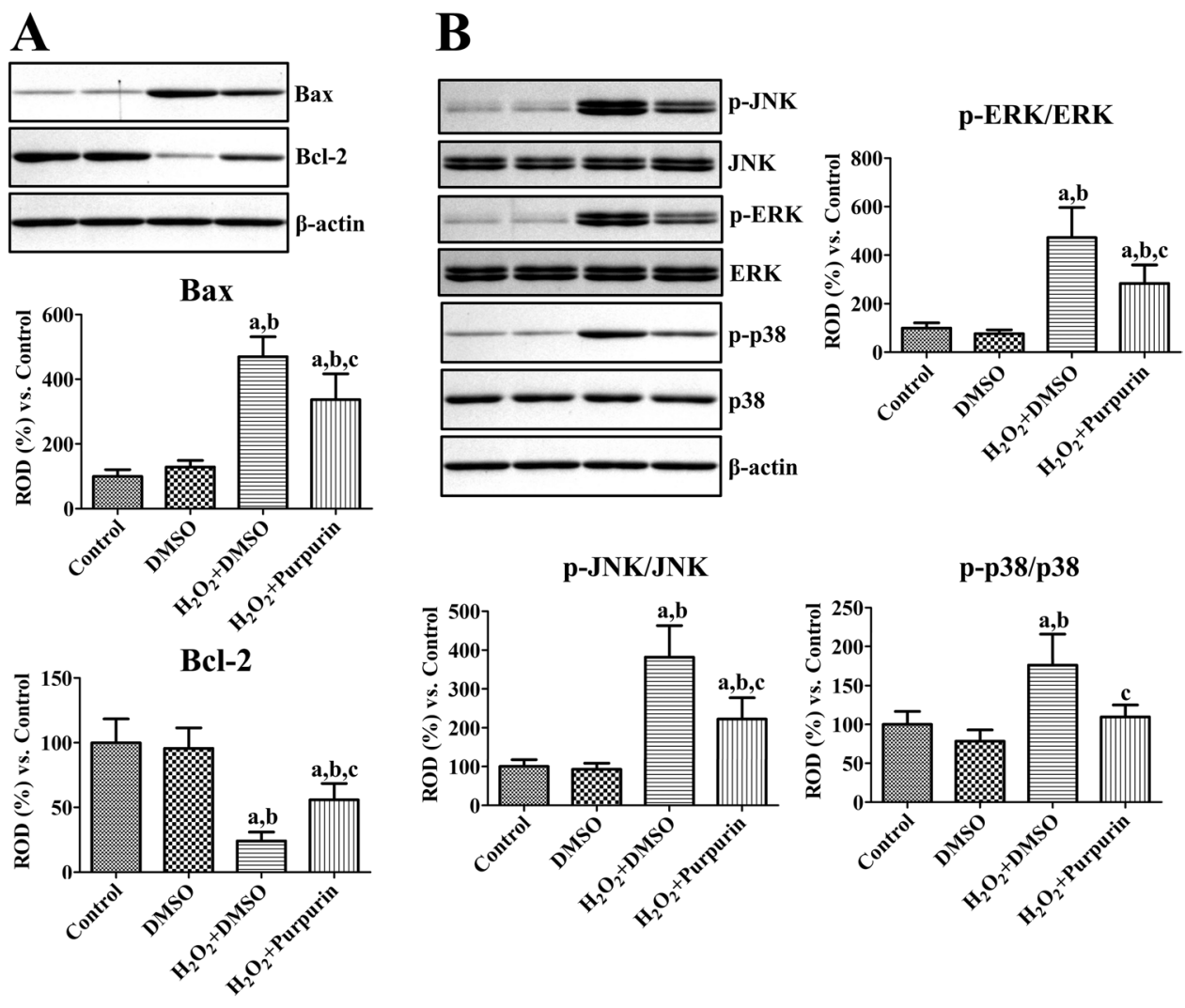

Fig. 2 Mechanisms of purpurin' effects against oxidative damage in HT22 cells. A Protein levels related to cell survival and death were measured after $\mathrm{H}_{2} \mathrm{O}_{2}$-induced oxidative stress in HT22 cells $2 \mathrm{~h}$ after $\mathrm{H}_{2} \mathrm{O}_{2}$ treatment using western blot analysis for Bax and Bcl-2, respectively. Protein levels of Bax and Bcl-2 were calibrated to the $\beta$-actin level. B Cell signaling pathway related to MAPKs were validated using western blot analysis for JNK, ERK, p38, and their phospho-

NeuN and Fluoro-Jade $\mathrm{C}$ in the hippocampus 4 days after ischemia. In the control group, abundant NeuN-immunoreactive cells were found in the hippocampus, while FluoroJade C stained cells were very few in the hippocampal CA1 region. In the vehicle-treated ischemic group, a few NeuNimmunoreactive cells were detected in the hippocampal CA1 region ( $5.1 \%$ of control), whereas in other regions, NeuNimmunoreactive cells were similar levels were seen as in the control group. In contrast, Fluoro-Jade C stained cells were abundantly detected in the hippocampal CA1 region. In the 1 or $3 \mathrm{mg} / \mathrm{kg}$ purpurin-treated groups, NeuN-immunoreactive neurons were similarly observed in the hippocampal CA1 region compared to vehicle-treated group (7.5\% and $9.9 \%$ of control). In the $6 \mathrm{mg} / \mathrm{kg}$ purpurin-treated ischemic group, many NeuN-immunoreactive cells were found in the CA1 region, and the number of NeuN-immunoreactive neurons was significantly higher $(60.2 \%$ of control) than that in the vehicle-treated ischemic group (Fig. 3B). In this group, Fluoro-Jade $\mathrm{C}$ stained cells were numerous in the hippocampal CA1 region, but the number of Fluoro-Jade $\mathrm{C}$ stained rylated forms $2 \mathrm{~h}$ after $\mathrm{H}_{2} \mathrm{O}_{2}$ treatment. Protein levels were converted into $\mathrm{p}-\mathrm{JNK} / \mathrm{JNK}$, p-ERK/ERK, and p-p38/p38 ratios in each group. $\mathbf{A}$ and $\mathbf{B}$ Data are expressed as mean value \pm standard deviation and were analyzed using one-way ANOVA followed by Bonferroni's post hoc test $\left({ }^{\mathrm{a}} p<0.05\right.$, significantly different from the control group; ${ }^{\mathrm{b}} p<0.05$, significantly different from the DMSO group; ${ }^{\mathrm{c}} p<0.05$, significantly different from the $\mathrm{H}_{2} \mathrm{O}_{2}+$ DMSO group)

cells was significantly decreased to $42.8 \%$ of vehicle-treated group (Fig. 3C).

\section{Neuroprotective Mechanisms of Purpurin's Effects Against Ischemic Damage in Gerbils}

The neuroprotective mechanisms of $6 \mathrm{mg} / \mathrm{kg}$ purpurin were evaluated in terms of anti-inflammatory responses in the hippocampus using an ELISA assay for IL-1 $\beta$, IL-6, and TNF- $\alpha 6 \mathrm{~h}$ after ischemia. In the vehicle-treated ischemic group, IL-1 $\beta$, IL- 6 , and TNF- $\alpha$ levels were significantly higher at $529.6 \%, 312.4 \%$, and $1255.0 \%$ of those in the control group, respectively, $6 \mathrm{~h}$ after ischemia. IL-1 $\beta$, IL-6, and TNF- $\alpha$ levels were significantly decreased 4 days in the hippocampus after ischemia compared to $6 \mathrm{~h}$ post-ischemic group, respectively. In the purpurin-treated ischemic group, IL- $1 \beta$, IL- 6 , and TNF- $\alpha$ levels were significantly lower than those in vehicle-treated ischemic group and were $203.2 \%$, $178.2 \%$, and $626.1 \%$ of those in the control group $6 \mathrm{~h}$ after ischemia, respectively. In addition, they decreased 4 days 
Fig. 3 Effect of purpurin against ischemic damage in gerbils. A Traveled distance and cumulative duration was measured in gerbils 1 day after ischemia in sham-operated (control), ischemia-induced vehicletreated (vehicle), and ischemiainduced purpurin-treated (purpurin) groups ( $n=10$ per group). B Mature neurons are visualized to show the surviving neurons after ischemic damage in the control, vehicle, and purpurin groups using NeuN immunohistochemical staining. C Cell death are detected in the control, vehicle, and purpurin groups using NeuN immunohistochemical staining. SO, stratum oriens; SP, stratum pyramidale; $\mathrm{SR}$, stratum radiatum. Scale bar $=50 \mu \mathrm{m}$. The number of NeuN-immunoreactive neurons and Fluoro-Jade C stained cells is shown as a percentile value vs. control (or vehicle) group ( $n=10$ per group), respectively. $\mathbf{A}, \mathbf{B}$, and $\mathbf{C}$ Data are expressed as mean \pm standard deviation and were analyzed using oneway ANOVA followed by Bonferroni's post hoc test $\left({ }^{\mathrm{a}} p<0.05\right.$, significantly different from the control group; ${ }^{b} p<0.05$, significantly different from the vehicle group; ${ }^{c} p<0.05$, significantly different from the $1 \mathrm{mg} /$ kg Purpurin group; ${ }^{\mathrm{d}} p<0.05$, significantly different from the $3 \mathrm{mg} / \mathrm{kg}$ purpurin group)
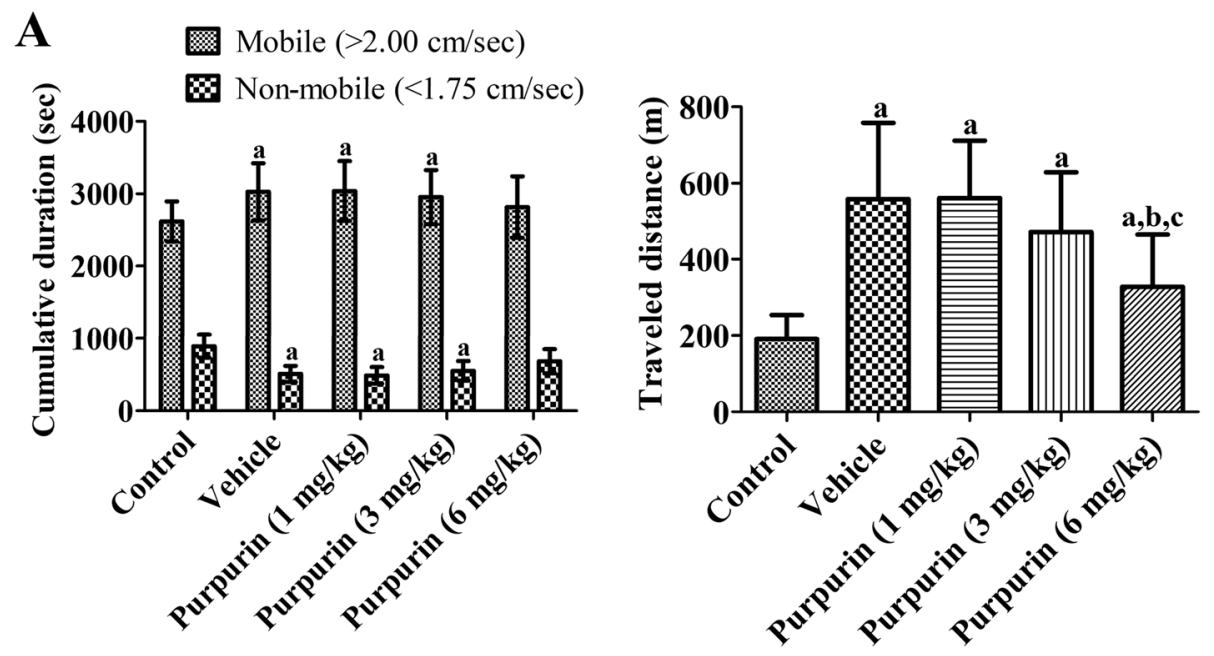

B
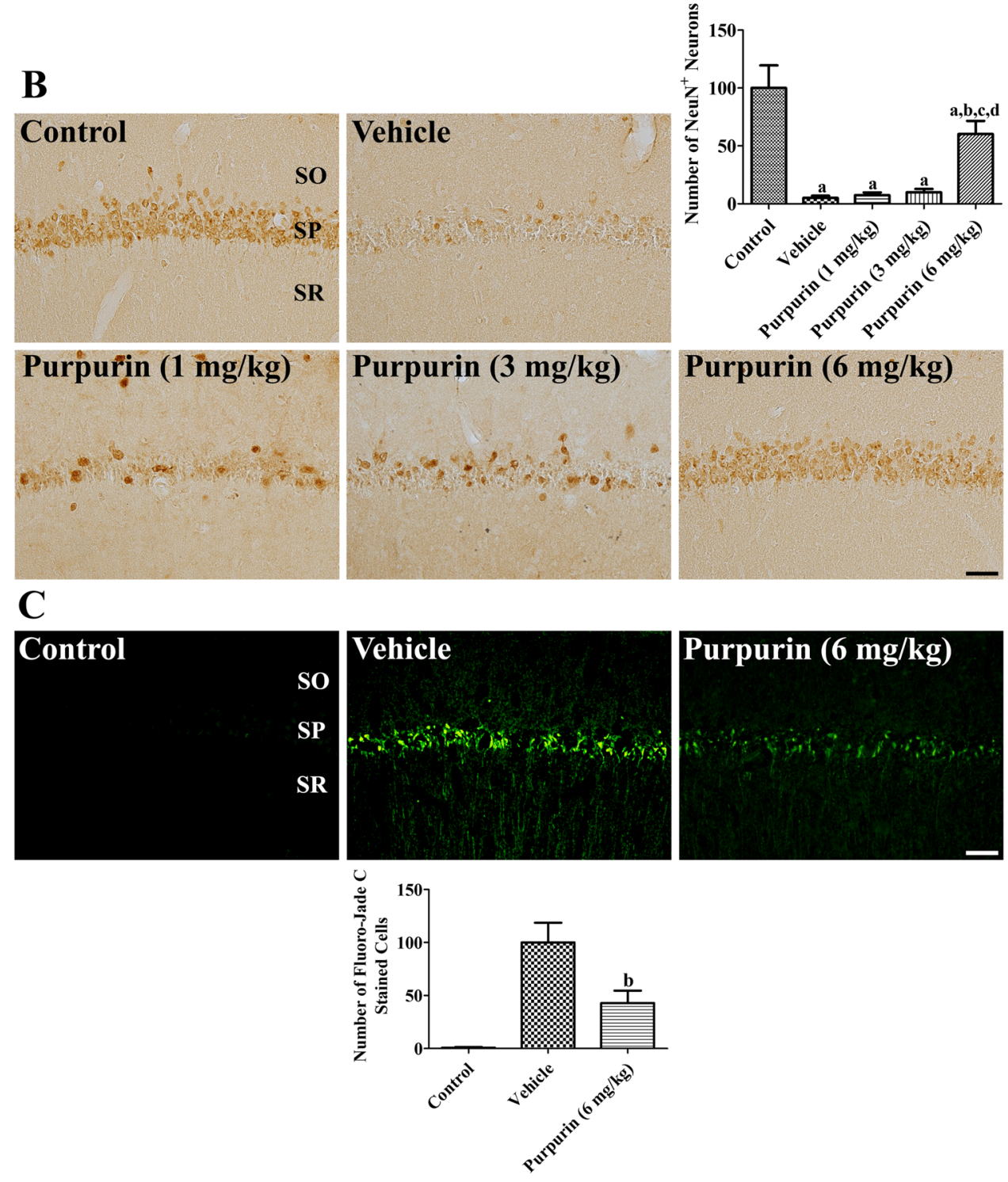
after ischemia, and there were no significant differences on the IL-1 $\beta$, IL- 6 , and TNF- $\alpha$ levels between vehicle- treated group and purpurin-treated group (Fig. 4A).

Microglia and astrocytes were visualized using immunohistochemical staining for Iba- 1 and GFAP 4 days after ischemia, respectively. In the control group, Iba-1 immunoreactive microglia had a small cell body and thin processes. In addition, GFAP immunoreactive astrocytes had small cytoplasm. In the vehicle-treated ischemic group, Iba-1 immunoreactive microglia in the stratum pyramidale had a round cell body, but they had a hypertrophied cell body and thick processes in the stratum oriens and radiatum. In addition, GFAP immunoreactive astrocytes had hypertrophied and punctuated cytoplasm with thickened processes. In this group, Iba-1 and GFAP immunoreactivity was significantly increased to $711.7 \%$ and $426.3 \%$ of those in the control group, respectively. In the purpurin-treated ischemic group, Iba-1 immunoreactive microglia had a large cell body and less-developed processes compared to those in the vehicletreated ischemic group. In addition, GFAP immunoreactive astrocytes had hypertrophied cytoplasm, but few punctuated cytoplasm. Higher in this group, Iba-1 and GFAP
Fig. 4 Anti-inflammatory mechanisms of purpurin against ischemic damage in gerbils. A Levels of pro-inflammatory cytokines were measured $6 \mathrm{~h}$ and 4 days after ischemia in the gerbil hippocampus of control, vehicle, and $6 \mathrm{mg} / \mathrm{kg}$ purpurin groups ( $n=5$ per group). B Microglia and astrocytes were visualized to show the morphological changes after ischemia in the CA1 region of the control, vehicle, and purpurin groups with Iba- 1 and GFAP immunohistochemical staining, respectively. In addition, NF- $\mathrm{\kappa B}$ immunohistochemical staining was conducted in the hippocampal CA1 region. SO, stratum oriens; SP, stratum pyramidale; $\mathrm{SR}$, stratum radiatum. Scale bar $=50 \mu \mathrm{m}$. Optical density was measured and expressed as a percentage of the value vs. control group ( $n=5$ per group). Data are expressed as mean value \pm standard deviation and were analyzed using one-way ANOVA followed by Bonferroni's post hoc test $\left({ }^{\mathrm{a}} p<0.05\right.$, significantly different from the control group; ${ }^{b} p<0.05$, significantly different from the vehicle group; ${ }^{c} p<0.05$, significantly different from the group $6 \mathrm{~h}$ after ischemia)

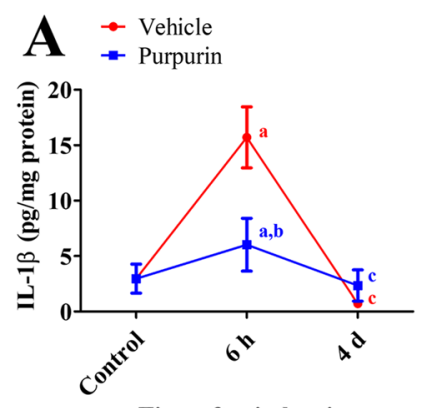

Time after ischemia
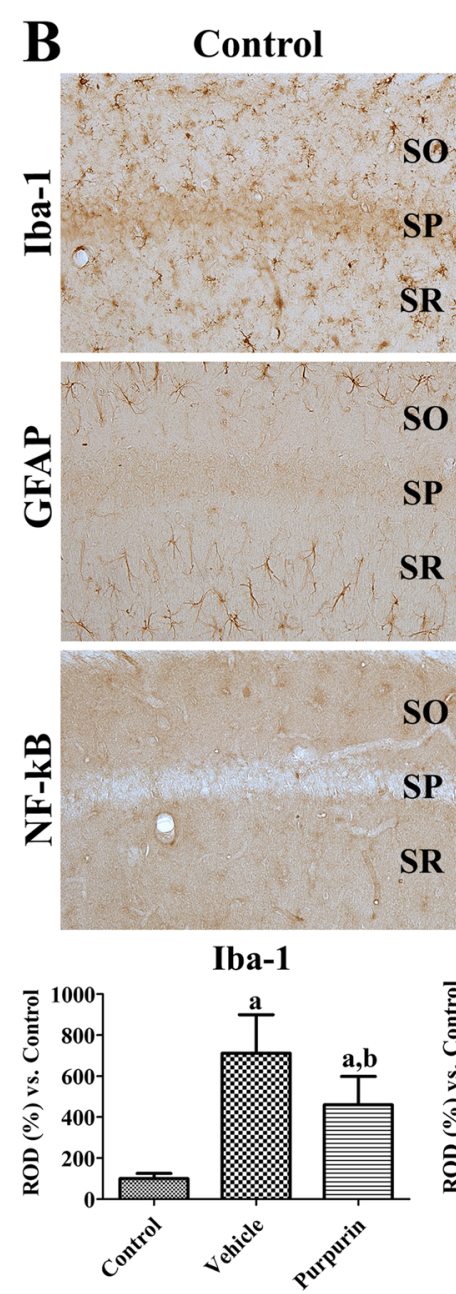

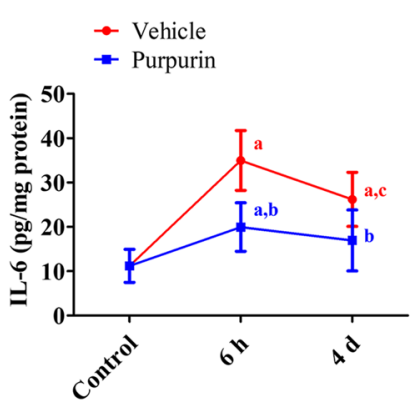

Time after ischemia

Vehicle
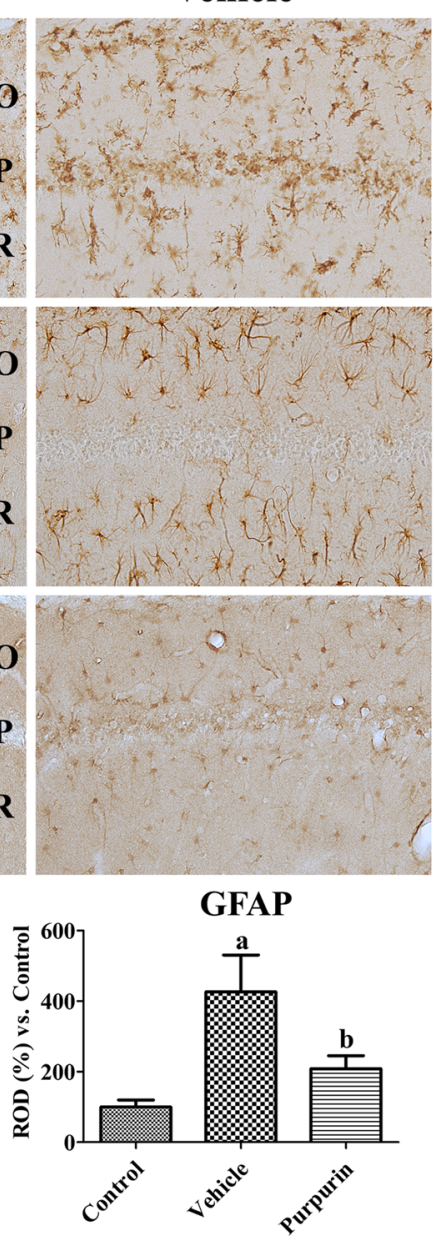

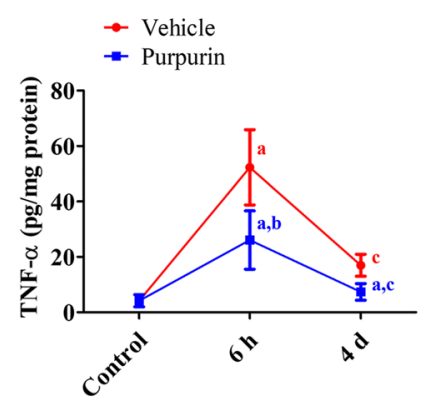

Time after ischemia

Purpurin

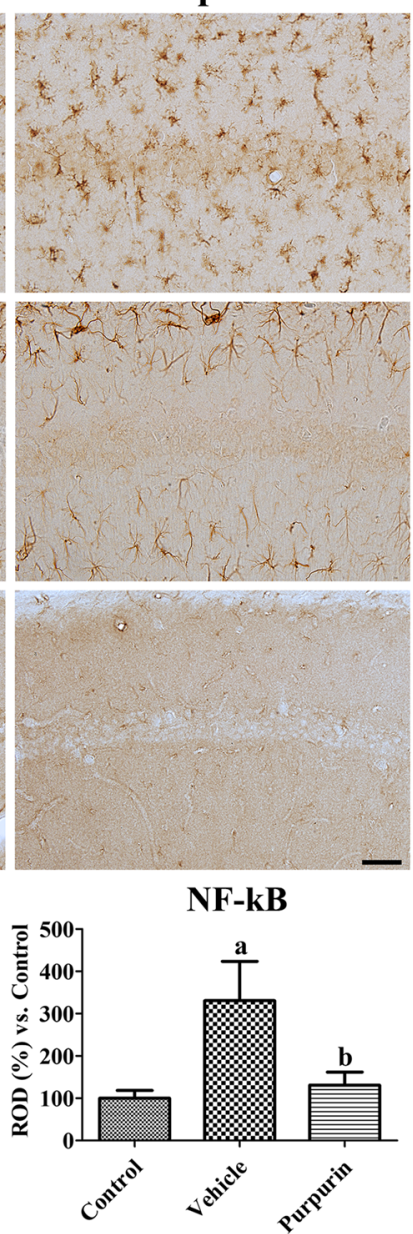


immunoreactivity was significantly higher than those in the vehicle-treated ischemic group and was $459.9 \%$ and $208.4 \%$ of those in the control group, respectively (Fig. 4B).

To elucidate the IL- $1 \beta$ - and TNF- $\alpha$-mediated activation of NF- $\kappa \mathrm{B}$ in the hippocampus after ischemia, NF- $\mathrm{\kappa B}$ immunohistochemical staining was conducted in the hippocampus 4 days after ischemia. In the control group, weak NF-kB immunoreactivity was detectable in the hippocampal $\mathrm{CA} 1$ region. In the vehicle-treated group, NF- $\mathrm{KB}$ immunoreactive structures were detected in the stratum oriens and radiatum 4 days after ischemia and NF- $\mathrm{\kappa B}$ immunoreactivity was significantly increased to $330.8 \%$ of control group. In the purpurin-treated group, NF- $\mathrm{KB}$ immunoreactivity was decreased to $131.0 \%$ of control group compared to that in the vehicle-treated group 4 days after ischemia (Fig. 4B).

MAPKs and their phosphorylated forms were validated using western blotting 1 day after ischemia in gerbil hippocampus and the ratio of phosphorylated and naïve forms were analyzed. In the vehicle-treated ischemic group, the ratios of p-JNK/JNK, p-ERK/ERK, and p-p38/p38 were significantly increased to $221.8 \%, 692.4 \%$, and $223.9 \%$ of control group, respectively, although naïve forms of MAPKs showed similar levels compared to respective control group. In the purpurin-treated ischemic group, the ratios of p-JNK/ JNK, p-ERK/ERK, and p-p38/p38 were significantly lowered to $129.9 \%, 406.0 \%$, and $124.2 \%$ of those in the control group compared to respective vehicle-treated ischemic group (Fig. 5A).

Bax and Bcl-2 protein levels were measured 1 day after ischemia in gerbils by western blot analysis. In the vehicletreated group, Bax protein levels were significantly increased to $224.4 \%$ of control group. In the purpurin-treated group, Bax levels were significantly decreased compared to that in the vehicle-treated group and was $142.2 \%$ of control group. However, there were no significant differences on Bcl-2 levels among groups $24 \mathrm{~h}$ after ischemia (Fig. 5B).

Oxidative stress was assessed by measuring MDA and hydroperoxides levels in the hippocampus 2 days after
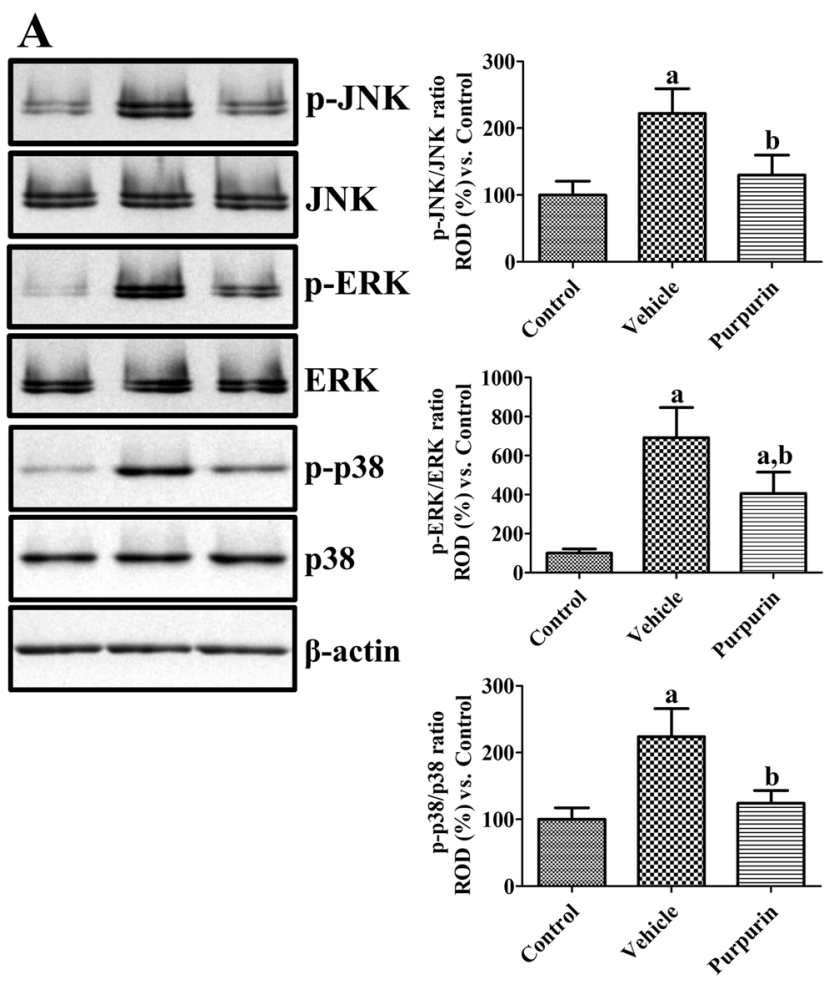

Fig. 5 MAPKs, Bax, Bcl-2, and oxidative stress effects of purpurin against ischemic damage in gerbils. A Protein levels of JNK, ERK, p38, and their phosphorylated forms were validated 1 day after ischemia in the gerbil hippocampus of control, vehicle, and $6 \mathrm{mg} / \mathrm{kg}$ purpurin groups ( $n=5$ per group) using western blot analysis. Protein levels were converted into $\mathrm{p}-\mathrm{JNK} / \mathrm{JNK}$, p-ERK/ERK, and p-p38/p38 ratios in each group. B Protein levels related to cell survival and death were measured 1 day after ischemia in the gerbil hippocampus of control, vehicle, and $6 \mathrm{mg} / \mathrm{kg}$ purpurin groups ( $n=5$ per group) using
B
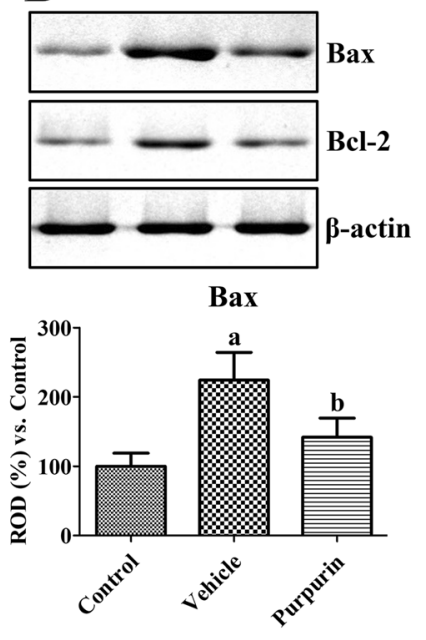

Bcl-2

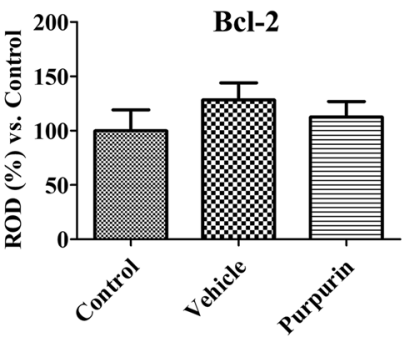

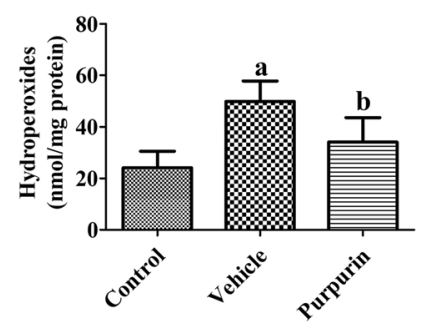

western blot analysis for Bax and Bcl-2, respectively. C MDA and hydroperoxides levels in the hippocampus 2 days after ischemia in the gerbil hippocampus of control, vehicle, and $6 \mathrm{mg} / \mathrm{kg}$ purpurin groups ( $n=5$ per group) using enzyme immunoassay. Data are expressed as mean value \pm standard deviation and were analyzed using one-way ANOVA followed by Bonferroni's post hoc test $\left({ }^{\mathrm{a}} p<0.05\right.$, significantly different from the control group; ${ }^{\mathrm{b}} p<0.05$, significantly different from the vehicle group) 
ischemia. MDA and hydroperoxides levels were significantly increased in the vehicle-treated group to $285.1 \%$ and $206.3 \%$ of control group, respectively. In the purpurintreated group, MDA and hydroperoxides levels were significantly decreased compared to those in vehicle-treated group and were $169.9 \%$ and $141.4 \%$ of control group, respectively (Fig. 5C).

\section{Discussion}

Purpurin, an alizarin-type anthraquinone, has free radical scavenging activity $[14,31-33]$ and antioxidant effects against Trp-P-2 carcinogen by reducing DNA adducts in the liver [34]. In the present study, we investigated the role of purpurin against oxidative stress induced by $\mathrm{H}_{2} \mathrm{O}_{2}$ in HT22 cells and against ischemic damage in gerbils. First, we screened the toxicity of purpurin in HT22 cells to determine the optimal concentration without toxicity in HT22 cells. We observed that $25-\mu \mathrm{M}$ purpurin was the optimal concentration with minimal toxicity in HT22 cells. The optimal concentration may differ depending on the cell type. In 3T3-L1 adipose cells, $50-$ and $100-\mu \mathrm{M}$ purpurin had positive effects [33].

Oxidative stress was induced by treatment with $\mathrm{H}_{2} \mathrm{O}_{2}$, which increases ROS formation and decreases cell viability in a concentration-dependent manner in HT22 cells [35]. Treatment with $\mathrm{H}_{2} \mathrm{O}_{2}$ significantly increased ROS formation and DNA fragmentation in HT22 cells, whereas it decreased cell viability. In the present study, we analyzed the ROS formation, DNA fragmentation, and cell viability at different time points after $\mathrm{H}_{2} \mathrm{O}_{2}$ treatment due to ROS formation at early time points, DNA fragmentation at late period, and neuronal death at most late time point. Purpurin treatment significantly ameliorated $\mathrm{H}_{2} \mathrm{O}_{2}$-induced ROS formation, DNA fragmentation, and decreased cell viability in HT22 cells. This result was supported by previous studies showing that purpurin has $\mathrm{H}_{2} \mathrm{O}_{2}$ scavenging activity and reduces ROS levels in activated RAW 264.7 murine macrophages [14]. In addition, purpurin reduces $h$ Tau accumulation in an in vitro culture system [18].

Next, we confirmed the protein levels of Bax and Bcl2 , which are the main components of the pro-apoptotic and anti-apoptotic pathways, respectively, at the same time point analyzed with cell viability, because high levels of ROS lead to mitochondrial membrane damage and release of pro-apoptotic proteins such as Bax [36]. Treatment with $\mathrm{H}_{2} \mathrm{O}_{2}$ significantly increased Bax levels and decreased Bcl-2 levels in HT22 cells, consistent with previous studies $[35,37]$. Incubation with purpurin significantly ameliorated the changes in $\mathrm{Bax}$ and $\mathrm{Bcl}-2$ induced by $\mathrm{H}_{2} \mathrm{O}_{2}$ treatment in HT22 cells. We also observed the phosphorylation of MAPKs, including JNK, ERK, and p38, because
MAPKs play important roles in ROS-induced cell death and $\mathrm{H}_{2} \mathrm{O}_{2}$ significantly increased the expression of $\mathrm{p}$-ERK 1/2, p-JNK, and p-p38 in HT22 cells [35]. Treatment with $\mathrm{H}_{2} \mathrm{O}_{2}$ significantly increased the $\mathrm{p}-J N K / J N K$, p-ERK/ERK, and p-p38/p38 ratios in HT22 cells, and incubation with purpurin significantly mitigated the increase in the ratio.

In the present study, we also investigated the effects of purpurin against ischemic damage following oral treatment with $6 \mathrm{mg} / \mathrm{kg}$ purpurin because purpurin is able to cross the blood brain barrier [18, 38]. In addition, purpurin caused no significant changes in physiological or blood chemistry variables in an acute oral toxicity study [39]. We observed the locomotor activity 1 day after ischemia because the locomotor test is a predictive measure for assessing neuronal damage in the hippocampus during the first 2 days after ischemia and thereafter the locomotor activity is decreased gradually [40, 41]. Transient forebrain ischemia significantly increased the travel distance and time in the mobile phase, indicating hyperactivity in gerbils 1 day after ischemia. Purpurin treatment significantly reduced the travel distance and time in the mobile phase, which suggests the reduction of functional damage in the hippocampus 1 day after ischemia. In addition, we observed that $6 \mathrm{mg} / \mathrm{kg}$, not 1 or $3 \mathrm{mg} / \mathrm{kg}$, purpurin treatment ameliorated the ischemia-induced reduction in NeuN-immunoreactive neurons in the hippocampal CA1 region. We confirmed that treatment with $6 \mathrm{mg} / \mathrm{kg}$ purpurin significantly decreased ischemia-induced degenerating neurons in the hippocampal CA1 region based on the Fluoro-Jade C staining, which is a reliable marker for degenerating neuronal cells during all differentiation stages [42]. This result suggests that purpurin has the potential to reduce neuronal death induced by ischemia.

To elucidate the possible role of $6 \mathrm{mg} / \mathrm{kg}$ purpurin against ischemia, we observed the morphology of astrocytes and microglia as well as pro-inflammatory cytokines in the hippocampus because a recent study showed the anti-inflammatory roles of purpurin in RAW 264.7 murine macrophage cells [14]. The animals were sacrificed $6 \mathrm{~h}$ after ischemia to measure IL- $1 \beta$, IL- 6 , and TNF- $\alpha$ levels in the hippocampus because these levels are significantly increased in the early period of ischemia [29, 30, 43]. In addition, the IL-1 receptor antagonist showed neuroprotective effects against ischemic damage in rats [44]. In the vehicle-treated group, IL-1 $\beta$, IL-6, and TNF- $\alpha$ levels were significantly increased $6 \mathrm{~h}$ after ischemia/reperfusion compared to those in the control group. In the purpurin-treated ischemic group, IL-1 $\beta$, IL-6, and TNF- $\alpha$ levels were dramatically lower in the hippocampal homogenates. This result suggests that purpurin treatment significantly reduces the release of pro-inflammatory cytokines in the hippocampus $6 \mathrm{~h}$ after ischemia. However, in the present study, we did not observe any significant differences on the IL-1 $\beta$, IL- 6 , and TNF- $\alpha$ levels between 
vehicle- and purpurin-treated group 4 days after ischemia/ reperfusion.

Next, we confirmed the activation of microglia and astrocytes based on their morphologies in the hippocampal CA1 region 4 days after ischemia. In the vehicle-treated group, Iba-1 immunoreactive microglia had hypertrophied cell body and thickened processes (activated microglia), and the phagocytic form (round cell body without processes) of microglia was also found in the stratum pyramidale of the CA1 region 4 days after ischemia/reperfusion. In addition, GFAP immunoreactive astrocytes had hypertrophied and punctuated cytoplasm (reactive astrocytes) in the hippocampal CA1 region, which has functions as phagocytes after transient ischemia injury [45]. This result was consistent with previous studies showing that ischemia-induced activation of microglia and astrocytes and their morphological changes in the hippocampus [46-49]. Treatment with purpurin reduced the phagocytic form of microglia in the stratum pyramidale and reactive astrocytes in the stratum radiatum and oriens. Overall Iba-1 and GFAP immunoreactivity was significantly decreased in the hippocampal CA1 region compared to those in the vehicle-treated group. A molecular docking study demonstrated that purpurin had a strong inhibitory effect on the nucleotide-binding domain leucine-rich repeat and pyrin domain containing receptor 3, which is one of the main contributors to neuroinflammation [50]. NF- $\mathrm{KB}$ is one of the important mediators in pathological process of ischemic damage, which can be activated by several inflammatory mediators [51]. In addition, NF- $\mathrm{KB}$ was expressed in the astrocytes 2 days after ischemia in gerbils and peaked 4 days after ischemia [52]. In the present study, we observed significant increases of NF- $\mathrm{kB}$ immunoreactivity in the hippocampus 4 days after ischemia and the treatment with purpurin significantly decreased in the hippocampal CA1 region.

In the present study, we also observed that the ischemia significantly increased the ratios of p-JNK/JNK, p-ERK/ ERK, and p-p38/p38 in the gerbil hippocampus 1 day after ischemia result. This result is consistent with in vitro study in HT22 cells that oxidative stress induced by $\mathrm{H}_{2} \mathrm{O}_{2}$ treatment significantly increased the phosphorylation of MAPKs. In addition, several studies demonstrate the increases of MAPK phosphorylation in the hippocampus after ischemia $[24,53,54]$ and treatment with JNK blocker ameliorates the neuronal death induced by ischemia [55]. In addition, the close relationship has been reported between the cytokinerelated inflammation and MAPKs [56, 57]. In the present study, we observed that the purpurin treatment significantly decreased the activation of MAPK pathway in the hippocampus after ischemia.

We observed Bax and Bcl-2 levels in the hippocampus $24 \mathrm{~h}$ after ischemia. In addition, we measured MDA and hydroperoxides levels in the hippocampus 2 days after ischemia to elucidate the mechanisms of MAPKs, Bax, and oxidative stress cascades activation. Transient forebrain ischemia significantly elevated Bax levels 1 day after ischemia, while Bcl-2 protein levels did not show any significant difference between groups although slight increases of $\mathrm{Bcl}-2$ protein was found in vehicle-treated ischemic group. This result was supported by previous studies that transient forebrain ischemia increases both apoptotic and anti-apoptotic pathways after ischemia, but the increase of anti-apoptotic signals was relatively low $[58,59]$. Treatment with purpurin significantly ameliorated the increases of Bax levels induced by ischemia, suggesting that treatment with purpurin decreases ischemia-induced apoptotic pathway. Oxidative stress measured by MDA and hydroperoxides levels was significantly increased 2 days after ischemia to confirm the antioxidant effects of purpurin in the hippocampus after ischemia. Treatment with purpurin significantly abrogated the ischemia-induced oxidative damage in the hippocampus. This result suggests that purpurin has potentials to reduce the ischemia-induced oxidative damage such as MDA and hydroxides.

\section{Conclusions}

The current findings suggest that purpurin may be a strong neuroprotective agent in HT22 cells and gerbil hippocampus to ameliorate MAPKs, Bax, and oxidative stress cascades activation after oxidative stress or ischemic damage.

Acknowledgements The authors are grateful to Ms. Hyun Sook Kim for providing the technical support to carry out this work.

Author Contribution W.K., H.J.K, H.Y.J., K.R.H., Y.S.Y., I.K.H, S.Y.C., and D.W.K. conceived the study. W.K., H.J.K., S.Y.C., and D.W.K. designed the study and wrote the manuscript. W.K., H.Y.J., and K.R.H. conducted the animal experiments. H.J.K., D.W.K., and S.Y.C. conducted biochemical experiments. Y.S.Y. and I.K.H participated in designing and discussing the animal study. All authors read and approved the manuscript and all data were generated in-house and that no paper mill was used.

Funding This work was supported by Basic Science Research Program through the National Research Foundation of Korea (NRF) funded by the Ministry of Science and ICT (NRF-2018R1A2B6001941 to Dae Won Kim) and by the Ministry of Education (NRF2019R1A6A1A11036849 to Soo Young Choi).

Data Availability The datasets and supporting materials generated during and/or analyzed during the current study are available from the corresponding author on reasonable request.

\section{Declarations}

Ethical Approval The experimental protocols were approved by the Institutional Animal Care and Use Committee (IACUC) of Seoul National University (SNU-200313-2). 
Consent to Participate Not applicable.

Consent to Publish Not applicable.

Competing Interests The authors declare no competing interests.

Open Access This article is licensed under a Creative Commons Attribution 4.0 International License, which permits use, sharing, adaptation, distribution and reproduction in any medium or format, as long as you give appropriate credit to the original author(s) and the source, provide a link to the Creative Commons licence, and indicate if changes were made. The images or other third party material in this article are included in the article's Creative Commons licence, unless indicated otherwise in a credit line to the material. If material is not included in the article's Creative Commons licence and your intended use is not permitted by statutory regulation or exceeds the permitted use, you will need to obtain permission directly from the copyright holder. To view a copy of this licence, visit http://creativecommons.org/licenses/by/4.0/.

\section{References}

1. Thrift AG, Thayabaranathan T, Howard G, Howard VJ, Rothwell PM, Feigin VL, Norrving B, Donnan GA et al (2017) Global stroke statistics. Int J Stroke 12:13-32

2. Lee TK, Kim H, Song M, Lee JC, Park JH, Ahn JH, Yang GE, $\mathrm{Kim} \mathrm{H}$ et al (2019) Time-course pattern of neuronal loss and gliosis in gerbil hippocampi following mild, severe, or lethal transient global cerebral ischemia. Neural Regen Res 14:1394-1403

3. Rashad S, Saigusa D, Yamazaki T, Matsumoto Y, Tomioka Y, Saito R, Uruno A, Niizuma K et al (2020) Metabolic basis of neuronal vulnerability to ischemia; an in vivo untargeted metabolomics approach. Sci Rep 10:6507

4. Richards EM, Fiskum G, Rosenthal RE, Hopkins I, McKenna MC (2007) Hyperoxic reperfusion after global ischemia decreases hippocampal energy metabolism. Stroke 38:1578-1584

5. Balaban RS, Nemoto S, Finkel T (2005) Mitochondria, oxidants, and aging. Cell 120:483-495

6. Yang J, Qi J, Xiu B, Yang B, Niu C, Yang H (2019) Reactive oxygen species play a biphasic role in brain ischemia. J Invest Surg 32:97-102

7. Rodriguez C, Agulla J, Delgado-Esteban M (2021) Refocusing the brain: new approaches in neuroprotection against ischemic injury. Neurochem Res 46:51-63

8. Bulua AC, Simon A, Maddipati R, Pelletier M, Park H, Kim KY, Sack MN, Kastner DL et al (2011) Mitochondrial reactive oxygen species promote production of proinflammatory cytokines and are elevated in TNFR1-associated periodic syndrome (TRAPS). J Exp Med 208:519-533

9. Minutoli L, Puzzolo D, Rinaldi M, Irrera N, Marini H, Arcoraci V, Bitto A, Crea G et al (2016) ROS-mediated NLRP3 inflammasome activation in brain, heart, kidney, and testis ischemia/ reperfusion injury. Oxid Med Cell Longev 2016:2183026

10. Kim YC (2010) Neuroprotective phenolics in medicinal plants. Arch Pharm Res 33:1611-1632

11. Putteeraj M, Lim WL, Teoh SL, Yahaya MF (2018) Flavonoids and its neuroprotective effects on brain ischemia and neurodegenerative diseases. Curr Drug Targets 19:1710-1720

12. Kumar M, Chandel M, Kumar S, Kaur S (2012) Amelioration of oxidative stress by anthraquinones in various in vitro assays. Asian Pac J Trop Dis 2:S692-S698

13. Kang K, Fong WP, Tsang PW (2010) Novel antifungal activity of purpurin against Candida species in vitro. Med Mycol 48:904-911
14. Nam W, Kim SP, Nam SH, Friedman M (2017) Structure-antioxidative and anti-inflammatory activity relationships of purpurin and related anthraquinones in chemical and cell assays. Molecules 22:E265

15. Park H, Shim JS, Kim BS, Jung HJ, Huh TL, Kwon HJ (2014) Purpurin inhibits adipocyte-derived leucine aminopeptidase and angiogenesis in a zebrafish model. Biochem Biophys Res Commun 450:561-567

16. Lee HW, Ryu HW, Kang MG, Park D, Oh SR, Kim H (2017) Selective inhibition of monoamine oxidase A by purpurin, an anthraquinone. Bioorg Med Chem Lett 27:1136-1140

17. Ma L, Hu P, Zhang J, Cui W, Zhao X (2020) Purpurin exerted antidepressant-like effects on behavior and stress axis reactivity: evidence of serotonergic engagement. Psychopharmacology 237:887-899

18. Viswanathan GK, Shwartz D, Losev Y, Arad E, Shemesh C, Pichinuk E, Engel H, Raveh A et al (2020) Purpurin modulates Tau-derived VQIVYK fibrillization and ameliorates Alzheimer's disease-like symptoms in animal model. Cell Mol Life Sci 77:2795-2813

19. Ravid O, Elhaik Goldman S, Macheto D, Bresler Y, De Oliveira RI, Liraz-Zaltsman S, Gosselet F, Dehouck L et al (2018) Blood-brain barrier cellular responses toward organophosphates: Natural compensatory processes and exogenous interventions to rescue barrier properties. Front Cell Neurosci $12: 359$

20. Candelario-Jalil E, Mhadu NH, Al-Dalain SM, Martínez G, León OS (2001) Time course of oxidative damage in different brain regions following transient cerebral ischemia in gerbils. Neurosci Res 41:233-241

21. Selakovic V, Korenic A, Radenovic L (2011) Spatial and temporal patterns of oxidative stress in the brain of gerbils submitted to different duration of global cerebral ischemia. Int J Dev Neurosci 29:645-654

22. Kim W, Kwon HJ, Jung HY, Hahn KR, Yoon YS, Hwang IK, Choi SY, Kim DW. P27 protects neurons from ischemic damage by suppressing oxidative stress and increasing autophagy in the hippocampus. Int J Mol Sci 21:9496

23. Kim W, Kwon HJ, Jung HY, Yoo DY, Kim DW, Hwang IK (2020) Phosphoglycerate mutase 1 reduces neuronal damage in the hippocampus following ischemia/reperfusion through the facilitation of energy utilization. Neurochem Int 133:104631

24. Jung HY, Cho SB, Kim W, Yoo DY, Won MH, Choi GM, Cho TG, Kim DW et al (2018) Phosphatidylethanolamine-binding protein 1 protects CA1 neurons against ischemic damage via ERK-CREB signaling in Mongolian gerbils. Neurochem Int 118:265-274

25. Shimizu S, Simon RP, Graham SH (1997) Dimethylsulfoxide (DMSO) treatment reduces infarction volume after permanent focal cerebral ischemia in rats. Neurosci Lett 239:125-127

26. Babcock AM, Baker DA, Lovec R (1993) Locomotor activity in the ischemic gerbil. Brain Res 625:351-354

27. Lee TK, Kang IJ, Kim B, Sim HJ, Kim DW, Ahn JH, Lee JC, Ryoo S et al (2020) Experimental pretreatment with chlorogenic acid prevents transient ischemia-induced cognitive decline and neuronal damage in the hippocampus through anti-oxidative and anti-inflammatory effects. Molecules 25:3578

28. Radtke-Schuller S, Schuller G, Angenstein F, Grosser OS, Goldschmidt J, Budinger E (2016) Brain atlas of the Mongolian gerbil (Meriones unguiculatus) in CT/MRI-aided stereotaxic coordinates. Brain Struct Funct 221(Suppl 1):1-272

29. Saito K, Suyama K, Nishida K, Sei Y, Basile AS (1996) Early increases in TNF- $\alpha$, IL- 6 and IL- $1 \beta$ levels following transient cerebral ischemia in gerbil brain. Neurosci Lett 206:149-152

30. Jung HY, Kwon HJ, Kim W, Hwang IK, Choi GM, Chang IB, Kim DW, Moon SM (2021) Tat-endophilin A1 fusion protein protects neurons from ischemic damage in the gerbil hippocampus: A 
possible mechanism of lipid peroxidation and neuroinflammation mitigation as well as synaptic plasticity. Cells 10:357

31. Baghiani A, Charef N, Djarmouni M, Saadeh HA, Arrar L, Mubarak MS (2011) Free radical scanvenging and antioxidant effects of some anthraquinone derivatives. Med Chem 7:639-644

32. Zengin G, Degirmenci NS, Alpsoy L, Aktumsek A (2016) Evaluation of antioxidant, enzyme inhibition, and cytotoxic activity of three anthraquinones (alizarin, purpurin, and quinizarin). Hum Exp Toxicol 35:544-553

33. Nam W, Nam SH, Kim SP, Levin C, Friedman M (2019) Anti-adipogenic and anti-obesity activities of purpurin in 3T3-L1 preadipocyte cells and in mice fed a high-fat diet. BMC Complement Altern Med 19:364

34. Marczylo T, Sugiyama C, Hayatsu H (2003) Protection against Trp-P-2 DNA adduct formation in C57bl6 mice by purpurin is accompanied by induction of cytochrome P450. J Agric Food Chem 51:3334-3337

35. Zhao ZY, Luan P, Huang SX, Xiao SH, Zhao J, Zhang B, Gu $\mathrm{BB}, \mathrm{Pi}$ RB et al (2013) Edaravone protects HT22 neurons from $\mathrm{H}_{2} \mathrm{O}_{2}$-induced apoptosis by inhibiting the MAPK signaling pathway. CNS Neurosci Ther 19:163-169

36. Redza-Dutordoir M, Averill-Bates DA (2016) Activation of apoptosis signalling pathways by reactive oxygen species. Biochim Biophys Acta 1863:2977-2992

37. Kushairi N, Phan CW, Sabaratnam V, David P, Naidu M (2019) Lion's mane mushroom, Hericium erinaceus (Bull.: Fr.) Pers. suppresses $\mathrm{H} 2 \mathrm{O} 2$-induced oxidative damage and LPS-induced inflammation in HT22 hippocampal neurons and BV2 microglia. Antioxidants (Basel) 8:261

38. Cecchelli R, Aday S, Sevin E, Almeida C, Culot M, Dehouck L, Coisne C, Engelhardt B et al (2014) A stable and reproducible human blood-brain barrier model derived from hematopoietic stem cells. PLoS One 9:e99733

39. Bedi O, Krishan P (2020) Investigations on acute oral toxicity studies of purpurin by application of OECD guideline 423 in rodents. Naunyn Schmiedebergs Arch Pharmacol 393:565-571

40. Janać B, Radenović L, Selaković V, Prolić Z (2006) Time course of motor behavior changes in Mongolian gerbils submitted to different durations of cerebral ischemia. Behav Brain Res 175:362-373

41. Ramos-Zúñiga R, Gómez PU, Navarro Ruiz A, de Luquín AS, García-Estrada J (2008) Locomotor activity is a predictive test after global ischemia-reperfusion in Mongolian gerbils. Minim Invasive Neurosurg 51:87-90

42. Ikenari T, Kurata H, Satoh T, Hata Y, Mori T (2020) Evaluation of Fluoro-Jade $\mathrm{C}$ staining: specificity and application to damaged immature neuronal cells in the normal and injured mouse brain. Neuroscience 425:146-156

43. Suzuki S, Tanaka K, Nagata E, Ito D, Dembo T, Fukuuchi Y (1999) Cerebral neurons express interleukin-6 after transient forebrain ischemia in gerbils. Neurosci Lett 262:117-120

44. Pradillo JM, Murray KN, Coutts GA, Moraga A, Oroz-Gonjar F, Boutin H, Moro MA, Lizasoain I et al (2017) Reparative effects of interleukin-1 receptor antagonist in young and aged/co-morbid rodents after cerebral ischemia. Brain Behav Immun 61:117-126

45. Morizawa YM, Hirayama Y, Ohno N, Shibata S, Shigetomi E, Sui Y, Nabekura J, Sato K et al (2017) Reactive astrocytes function as phagocytes after brain ischemia via ABCA1-mediated pathway. Nat Commun 8:28
46. Hwang IK, Yoo KY, Kim DW, Choi SY, Kang TC, Kim YS, Won MH (2006) Ionized calcium-binding adapter molecule 1 immunoreactive cells change in the gerbil hippocampal CA1 region after ischemia/reperfusion. Neurochem Res 31:957-965

47. Anan'ina T, Kisel A, Kudabaeva M, Chernysheva G, Smolyakova V, Usov K, Krutenkova E, Plotnikov M et al (2020) Neurodegeneration, myelin loss and glial response in the three-vessel global ischemia model in rat. Int J Mol Sci 21:6246

48. Koizumi S, Hirayama Y, Morizawa YM (2018) New roles of reactive astrocytes in the brain; an organizer of cerebral ischemia. Neurochem Int 119:107-114

49. Pekny M, Wilhelmsson U, Tatlisumak T, Pekna M (2019) Astrocyte activation and reactive gliosis-a new target in stroke? Neurosci Lett 689:45-55

50. Chen DB, Gao HW, Peng C, Pei SQ, Dai AR, Yu XT, Zhou P, Wang Y et al (2020) Quinones as preventive agents in Alzheimer's diseases: focus on NLRP3 inflammasomes. J Pharm Pharmacol 72:1481-1490

51. Ridder DA, Schwaninger M (2009) NF-kappaB signaling in cerebral ischemia. Neuroscience 158:995-1006

52. Yoo KY, Yoo DY, Hwang IK, Park JH, Lee CH, Choi JH, Kwon $\mathrm{SH}, \mathrm{Her} \mathrm{S}$ et al (2011) Time-course alterations of Toll-like receptor 4 and NF- $\mathrm{KB}$ p65, and their co-expression in the gerbil hippocampal CA1 region after transient cerebral ischemia. Neurochem Res 36:2417-2426

53. Zablocka B, Dluzniewska J, Zajac H, Domańska-Janik K (2003) Opposite reaction of ERK and JNK in ischemia vulnerable and resistant regions of hippocampus: involvement of mitochondria. Brain Res Mol Brain Res 110:245-252

54. Ko IG, Jin JJ, Hwang L, Kim SH, Kim CJ, Jeon JW, Chung JY, Han JH (2021) Adenosine A2A receptor agonist polydeoxyribonucleotide ameliorates short-term memory impairment by suppressing cerebral ischemia-induced inflammation via MAPK pathway. PLoS One 16:e0248689

55. Carboni S, Antonsson B, Gaillard P, Gotteland JP, Gillon JY, Vitte PA (2005) Control of death receptor and mitochondrialdependent apoptosis by c-Jun $\mathrm{N}$-terminal kinase in hippocampal CA1 neurones following global transient ischaemia. J Neurochem 92:1054-1060

56. Nozaki K, Nishimura M, Hashimoto N (2001) Mitogen-activated protein kinases and cerebral ischemia. Mol Neurobiol 23:1-19

57. Kaminska B, Gozdz A, Zawadzka M, Ellert-Miklaszewska A, Lipko M (2009) MAPK signal transduction underlying brain inflammation and gliosis as therapeutic target. Anat Rec (Hoboken) 292:1902-1913

58. Niwa M, Hara A, Iwai T, Sassa T, Mori H, Uematsu T (1997) Expression of $\mathrm{Bax}$ and $\mathrm{Bcl}-2$ protein in the gerbil hippocampus following transient forebrain ischemia and its modification by phencyclidine. Neurol Res 19:629-633

59. Ferrer I, López E, Blanco R, Rivera R, Ballabriga J, Pozas E, Martí E (1998) Bcl-2, Bax, and Bcl-x expression in the CA1 area of the hippocampus following transient forebrain ischemia in the adult gerbil. Exp Brain Res 121:167-173

Publisher's Note Springer Nature remains neutral with regard to jurisdictional claims in published maps and institutional affiliations. 